\title{
Peripheral Ossifying Fibroma in Rare Site: A Clinicopathological Report
}

\author{
${ }^{1}$ Arati C Koregol, ${ }^{2}$ Nagaraj Kalburgi, ${ }^{3}$ Apoorva Kamat, ${ }^{4}$ Jane Mary, ${ }^{5}$ Ankita Kotecha
}

\begin{abstract}
Peripheral ossifying fibroma (POF) is a slowly growing benign tumor with a high recurrence rate. It is a common occurrence in the maxilla. A nodular mass, either pedunculated or sessile, usually emanating from the interdental papilla. Complete excision of the lesion, including the periosteum, is important to prevent recurrence.

Peripheral ossifying fibroma occurring in the mandible at the age of 50 in the posterior mandible is an occasional entity. This article describes a case of a female patient with a slowly growing pedunculated tumor in the posterior mandible, which was diagnosed as POF.
\end{abstract}

Keywords: Calcification, Peripheral ossifying fibroma, Recurrence.

How to cite this article: Koregol AC, Kalburgi N, Kamat A, Mary J, Kotecha A. Peripheral Ossifying Fibroma in Rare Site: A Clinicopathological Report. J Health Sci Res 2015;6(2):60-64.

Source of support: Nil

Conflict of interest: None

\section{INTRODUCTION}

Gingiva being constantly subjected to external and internal stimuli often has to host unwanted guests in the form of numerous localized growths ranging from developmental, reactive, and inflammatory to neoplastic in nature. Reactive lesions are the most common among all those occurring on the gingiva. These lesions represent an untoward reaction to any kind of irritation or lowgrade injury, such as chewing, trapped food, calculus, and fractured teeth and iatrogenic factors, such as overhanging restorations. The various hyperplastic lesions are very much similar in clinical appearance. As a result, periodontists and oral and maxillofacial surgeons often give diagnostic terms epulis to these lesions clinically. Diagnosis of each of these lesions from the subgroup is aided by their clinical and radiographic features, but histopathology is the key to diagnosis. ${ }^{1}$

\footnotetext{
1,2,5 Professor, ${ }^{3,4}$ Postgraduate Student

${ }^{1-5}$ Department of Periodontics, PMNM Dental College and Hospital, Bagalkot, Karnataka, India

Corresponding Author: Arati C Koregol, Professor, Department of Periodontics, PMNM Dental College and Hospital, Bagalkot Karnataka, India, Phone: +918354220289, e-mail: aratikperio@ yahoo.co.in
}

Ossifying fibroma is one such reactive lesion. According to the World Health Organization (WHO), odontogenic fibroma is a relatively rare benign odontogenic neoplasm. The term was coined by Eversole and Robin. ${ }^{2}$ There are two types of ossifying fibroma: The central type and the peripheral type. The central type arising from the endosteum or the periodontal ligament adjacent to the root apex causes expansion of the medullary cavity. The peripheral type occurs exclusively on the soft tissues only in the tooth-bearing areas of the jaws. ${ }^{3}$ Daley and Wysocki have reported peripheral ossifying fibroma (POF) to be the third most common odontogenic tumors and the most common peripheral odontogenic tumor. ${ }^{4}$

Peripheral ossifying fibroma is a localized reactive enlargement of the gingiva that usually measures less than $1.5 \mathrm{~cm}$ at its greatest dimension. It accounts for $9.6 \%$ of all biopsied lesions occurring more often in females than in males with a slight predilection for anterior maxilla, with more than $50 \%$ lesions occurring in the incisor canine region. They are most often associated with the papilla and have reported with potential to induce migration of teeth. ${ }^{5}$

The pathogenesis of the lesion is uncertain. It has also been reported to be a maturation of preexisting pyogenic granuloma or a peripheral giant cell granuloma.

About $60 \%$ tumors occur in the maxilla and more than $50 \%$ of all cases of maxillary POF are found in the incisors. The recurrence rate being high owing to its incomplete removal, the only way to ensure no recurrence is by ensuring the excision of the whole lesion. Here we present a rare location of a case of $\mathrm{POF}$ in the mandibular region. So the present case report aims to briefly review the current literature of this condition with special emphasis on clinicopathologic and histomorphologic features of POF and its precise surgical management to prevent further complications. ${ }^{3}$

\section{CASE REPORT}

A 50-year-old female patient reported to the Department of Periodontics, PMNM Dental College and Hospital, Bagalkot, Karnataka, with the chief complaint of swelling in lower front region since 3 months. The patient gave a history of similar growth 5 years ago, which was then excised in the same institution. The present swelling had been reported to be its recurrence and it had gradually increased in size to attain its present size. Basically her concern was about interference with mastication, and the 
associated pain due to impingement of the antagonist teeth upon the swelling had brought her to the institution. Her past medical history and drug history was otherwise noncontributory.

\section{Intraoral Examination}

Intraoral examination revealed a solitary swelling in the mandibular anterior region extending from distal aspect of 33 to distal aspect of 34, leading to displacement of involved teeth. Supero-inferiorly it projected above the occlusal plane and obliterated the vestibule. The growth extended lingually but was smaller than its labial counterpart. It measured approximately $4 \times 2 \mathrm{~cm}$, involving marginal, attached gingiva and interdental papilla of 33 and 34 . The overlying mucosa was erythematous in relation to 33 and of similar color to the surrounding mucosa in relation to 34 , with indentations corresponding to impingement by antagonist teeth. Surrounding tissue revealed gingival enlargement in relation to 31 and 32 (Fig. 1). On palpation, the swelling was firm in consistency and nontender. The patient exhibited a markedly poor oral hygiene with no other remarkable deformities either intraorally or extraorally.

A provisional diagnosis of irritational fibroma was rendered. Differential diagnosis was peripheral giant cell granuloma, $\mathrm{POF}$, pyogenic granuloma, osteosarcoma, and

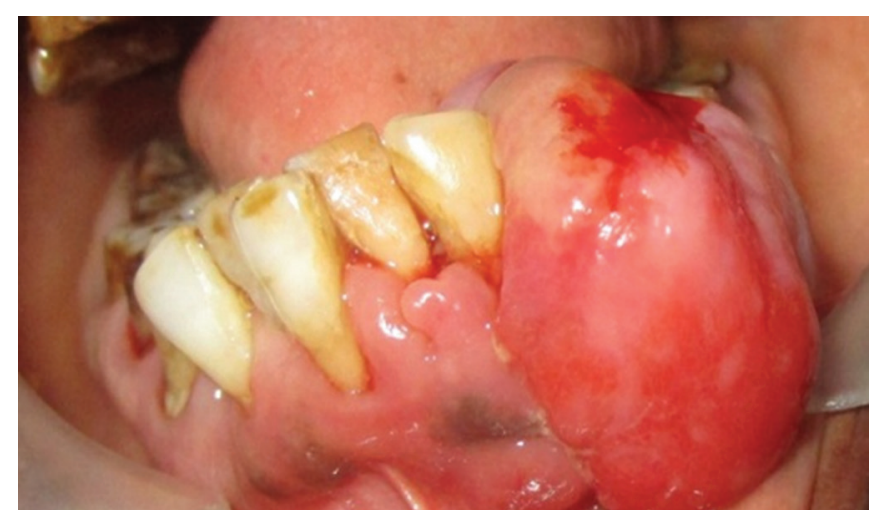

Fig. 1: Extent of lesion

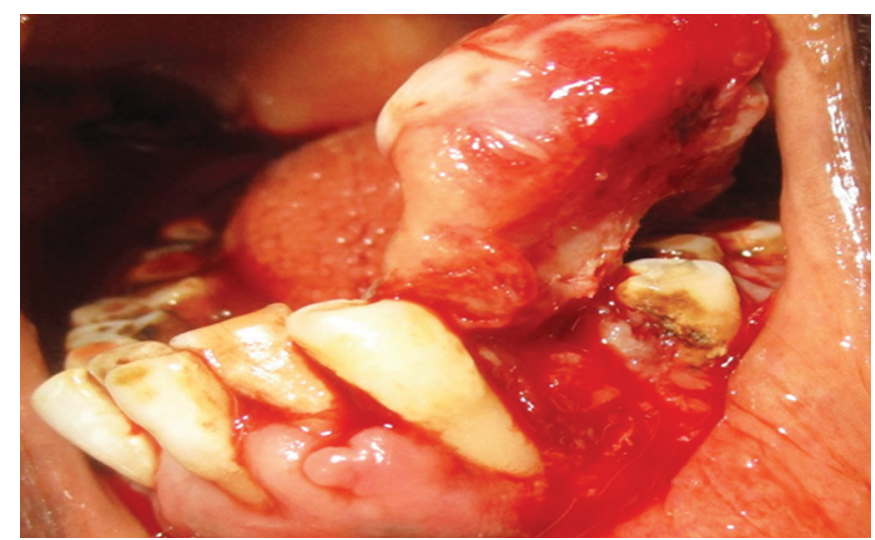

Fig. 3: Separation of lesion from its margins irritational fibroma. Intraoral periapical radiograph and orthopantomographs were advised for the same.

\section{RADIOGRAPHIC FEATURES}

The radiographic characteristics are always diagnostic. Radiographic investigations were done by intraoral periapical radiographs and orthopantomogram, which revealed homogeneous radiopacity in relation to 33 and 34 extending from distal aspect of 33 to distal aspect of 34 with a hint of calcified material at the centere. It measured around $4 \times 2 \mathrm{~cm}$ and was roughly ovoid in shape. Moderate amount of bone loss was seen in relation to 33, 34 , and -35 . Erosion of crestal bone was noted in relation to 34 and 35 . The lesion seemed to have caused a displacement of teeth in relation to 34 and 35.

Phase 1 therapy was performed thoroughly prior to surgical excision. After obtaining consent from the patient, surgical excision of the lesion was planned. The patient was advised a complete hemogram prior to surgery. Under local anesthesia, the lesion was excised to its depth (Fig. 2) by giving incision through the base of the growth, followed by thorough curettage to the depth of the lesion and surrounding tissues (Fig. 3). Intraoperatively a clear surgical field was maintained with the use of ethamsylate. Hemostatic agent was placed to achieve a clear surgical field (Fig. 4).

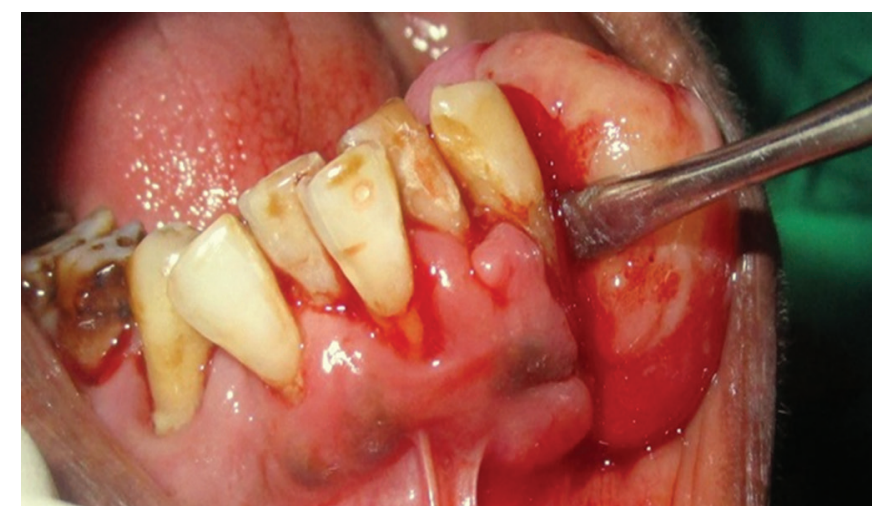

Fig. 2: Excision of lesion

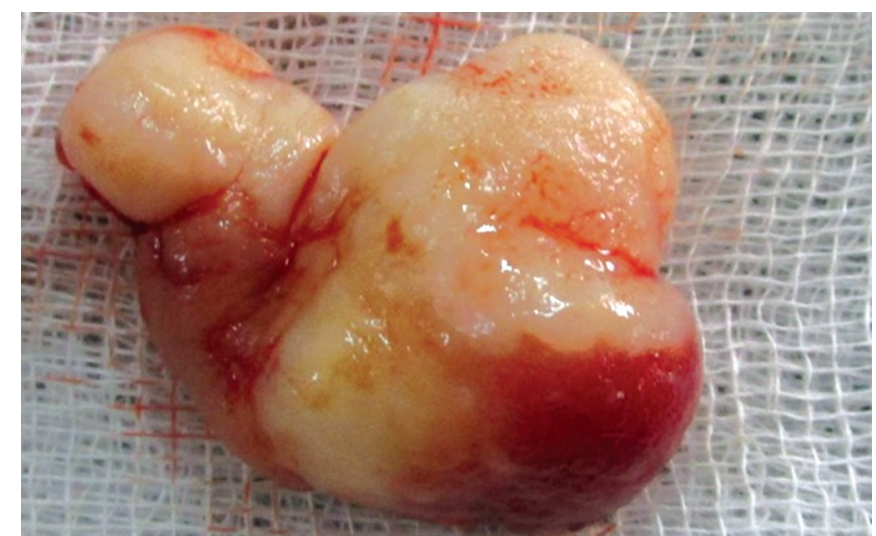

Fig. 4: Achieving hemostasis using a hemostatic agent 


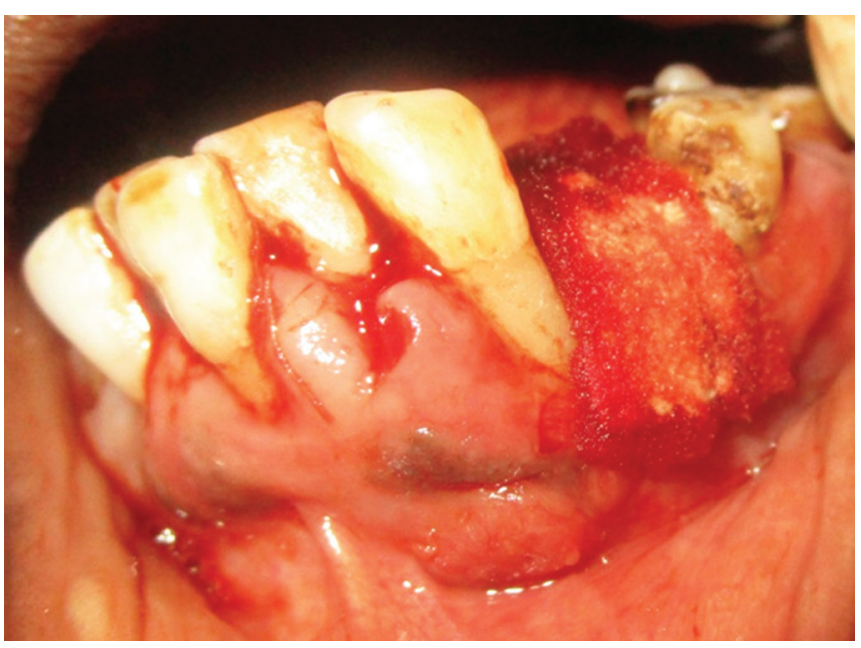

Fig. 5: Placement of periodontal pack

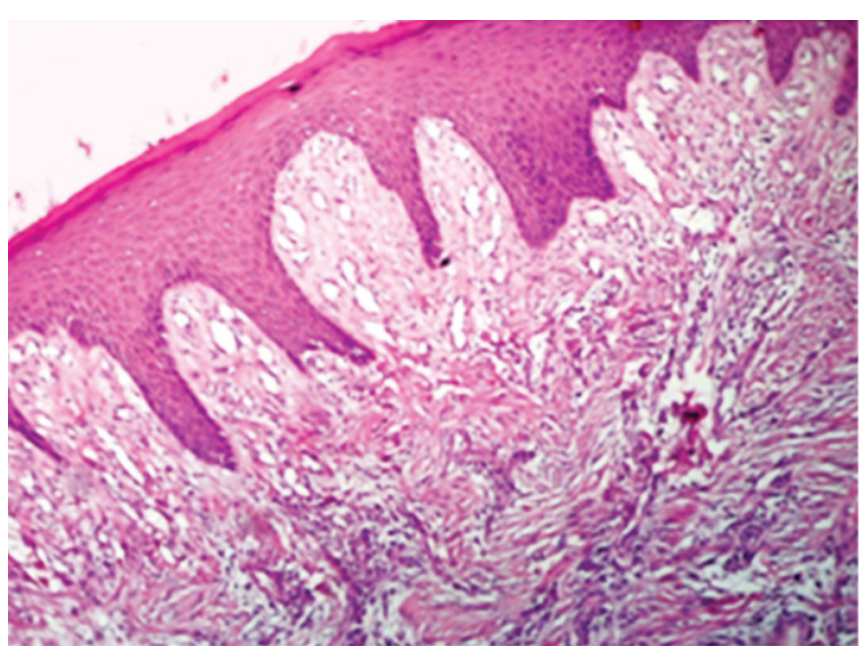

Fig. 7: Histopathology of lesion

Periodontal dressing was placed (Fig. 5) and patient was discharged. Patient was prescribed analgesics and antibiotic regimen. Patient was recalled after 1 week for removal of dressing and revaluation. The excised specimen was sent to department of oral pathology for histopathological evaluation (Fig. 6).

\section{HISTOPATHOLOGICAL REPORT}

\section{Macroscopic Features}

The histopathological report revealed one bit of tissue in formalin, measuring $4.00 \times 2.00 \mathrm{~cm}$, which was firm in consistency, brownish white in color, and irregular in shape.

\section{Microscopic Features}

The histopathological $\mathrm{H}$ and E-stained sections revealed parakeratinized stratified squamous epithelium overlying fibrocellular connective tissue with dense collagen fibers, relatively dense chronic inflammatory cell

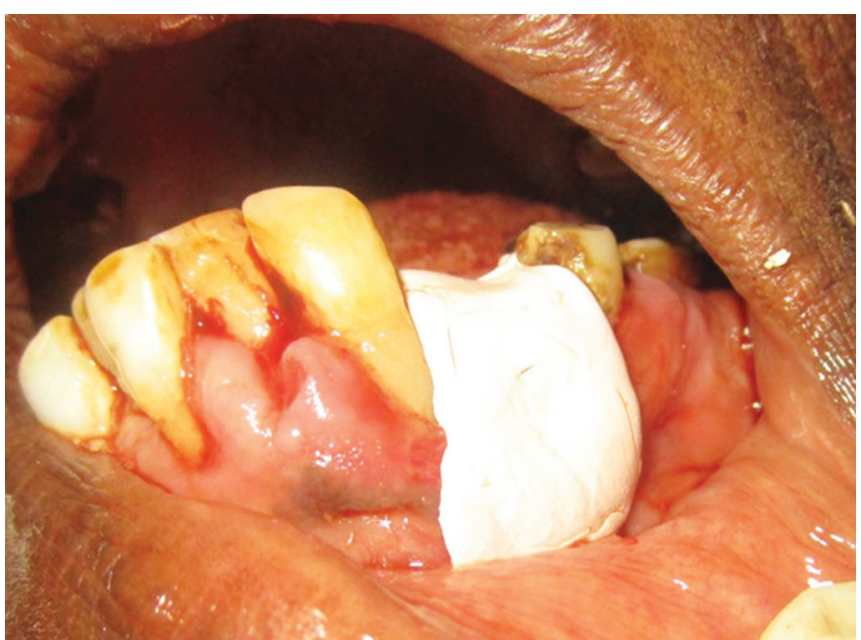

Fig. 6: Excised lesion

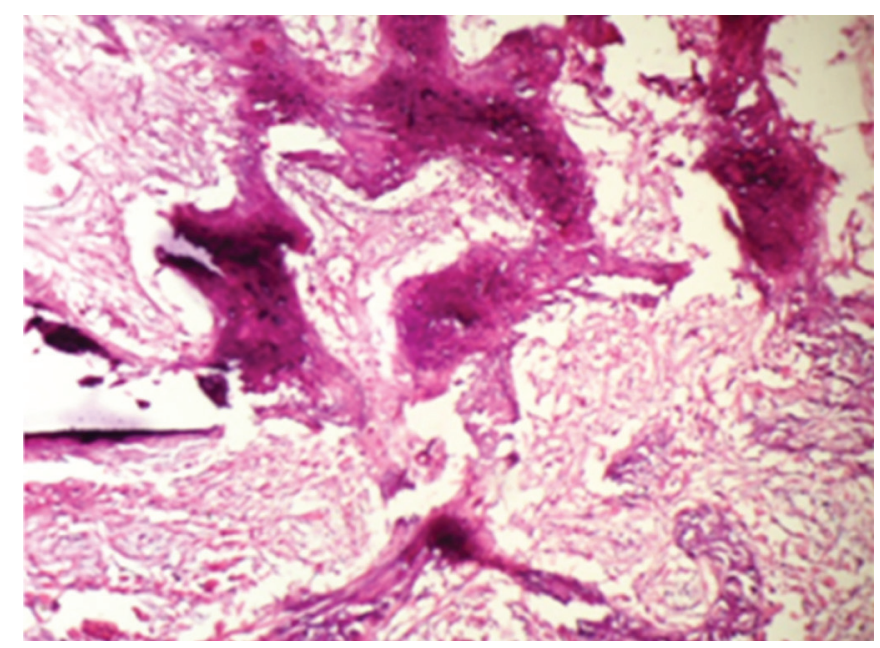

Fig. 8: Histopathology of lesion

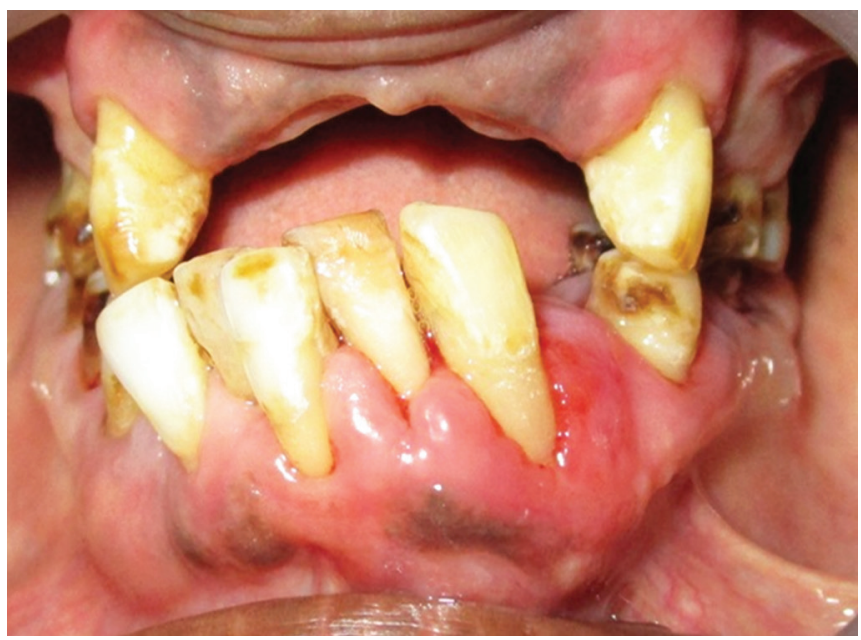

Fig. 9: Follow-up of 1 month

infiltrate, blood vessels, and areas of basophilic structures suggestive of calcification are evident (Figs 7 and 8). These overall histopathological features were suggestive of the final diagnosis of the lesion being a focal reactive over growth (POF). 


\section{DISCUSSION}

Peripheral ossifying fibroma is a clinical entity of periodontium, comprising nearly up to $2 \%$ of oral biopsied lesions. ${ }^{7}$ Other terms used in the past to describe this lesion were epulis, ossifying fibroma, peripheral fibroma with calcifications, and calcifying fibroblastic granuloma. ${ }^{8}$

Although the etiopathogenesis of POF is unclear, ${ }^{9-11}$ it has been suggested that these lesions arise in the cells of the periodontal ligament. Our case consolidates this pattern of occurrence. It predominantly affects females in the second decade of life, which can be attributed to various hormonal alterations, such as puberty, pregnancy, and others that a female experiences throughout the course of her life. Peripheral ossifying fibroma in our case had affected a female patient in her late forties, which can be due to her hormonal alterations concerned to menopause.

Peripheral ossifying fibroma occurs in the gingiva of the anterior maxilla. ${ }^{12,13}$ However, in our case, it had occurred in the mandibular anterior region rather than in the anterior maxilla, which in itself is a rare presentation. Various other factors, such as trauma and local irritants, that is, plaque and calculus, have been implicated in the etiopathogenesis of POF. These factors were also present in our case. The patient presented with noticeable local factors and trauma to the growth. ${ }^{10,11}$

On clinical examination, POF usually appears to be a well-defined and slow-growing gingival mass measuring nearly $2 \mathrm{~cm}$ and located in the interdental papilla region. ${ }^{79-11}$ Our case is similar to the clinical features described thus. Usually, the color of the growth is identical to that of the gingiva or slightly reddish and the surface may appear ulcerated. Our case also manifested in the similar fashion, that is, the overlying mucosa over roughly half of the growth was of a similar color as that of the surrounding tissues, whereas in the remaining half, it was erythematous. The erythematous mucosa and the associated pain could be attributed to the trauma or irritation caused by the antagonist teeth. ${ }^{9-11}$

The erosion of the crestal bone could be attributed to the fact that it was caused by the long-standing plaqueinduced inflammation and constant pressure caused by the overlying growth.

Firm consistency of POF explains the calcification and/or ossification present within the lesion. ${ }^{12,13}$ The definitive diagnosis is usually provided by histological examination ${ }^{12,13}$ with the identification of presence of foci of calcifications. ${ }^{9,12,14}$ Surgical excision of the lesion up to its base is the treatment of choice, although recurrence has been reported. After performing surgical excision, our case was diagnosed by histopathological evaluation.

Histologically, the POF appears to be a nonencapsulated mass of cellular fibroblastic connective tissue of mesenchymal origin, covered with stratified squamous epithelium, which is ulcerated in 23 to $66 \%$ of cases. ${ }^{14,15}$
They contain areas of fibrous connective tissue, endothelial proliferation, and mineralization. The mineralized component of POF varies, occurring in approximately 50 to $75 \%$ of cases. Mineralization can vary between cementum-like material, bone (woven and lamellar), and dystrophic calcification. ${ }^{14-16}$ These histological findings are correlating with findings of the present case, and diagnose it to be a case of POF. Tooth migration and bone destruction, though not common, have been reported in many cases. The POF lesion is generally small and does not require imaging beyond radiographs. ${ }^{11}$ This is in accordance with the findings of the present case.

The recurrence of POF is said to be around 50\%, which is an important aspect from clinical standpoint. This can be due to either incomplete excision or presence of putative factors, such as plaque and calculus. It is advisable to excise the lesion to its complete depth and eliminate the contributing putative factors so as to minimize the chances of recurrence. Recurrence in the present case can be ascribed to the presence of local factors, such as plaque and calculus and probably due to incomplete removal of growth previously. Keeping these facts in mind, we performed a thorough phase 1 therapy in the present case followed by surgical excision of the lesion.

\section{CONCLUSION}

Peripheral ossifying fibroma represents one of the enigmatic clinicopathological entities. Although a provisional diagnosis can be made by vigilant clinical examination, histopathologic evaluation remains the foundation for arriving at a definitive clinical diagnosis. Radiographic revelation of the involved teeth and excised lesion might supplement the diagnosis and add an insight to the disease entity by means of depicting foci of calcifications. Thorough phase 1 therapy to eliminate the putative factors and precise surgical excision of the lesion are the treatment of choice. Although the follow-up period in such cases remains undiscussed till date, it is judicious to keep such patients on regular follow-up to keep a check on their maintenance and note down any recurrence.

\section{CLINICAL SIGNIFICANCE}

Peripheral ossifying fibroma being a slowly progressing lesion, it takes quite some time before the patients seek treatment due to the lack of symptoms associated with the lesion. Treatment consists of a complete surgical excision of the lesion, followed by removal of all possible irritants. Close postoperative follow-up is required because of the high recurrence rate.

\section{ACKNOWLEDGMENT}

Authors acknowledge the Department of Oral Pathology and Microbiology, PMNM Dental College and Hospital, Bagalkot, for their support. 


\section{REFERENCES}

1. Reddy V, Saxena S, Saxena S, Reddy M. Reactive hyperplastic lesions of the oral cavity: a ten year observational study on North Indian Population. J Clin Exp Dent 2012 Jul;4(3): e136-e140.

2. Eversole LR, Robin S. Reactive lesions of gingiva. J Oral Pathol 1972;1(1):30-38.

3. Neville BW, Damn DD, Allen CM. Textbook of oral an maxillofacial pathology. 2nd ed. West Philadelphia (PA): Saunders; 2004. p. 451-452.

4. Ritwik P, Brannon R. Peripheral odontogenic fibroma: a clinicopathologic study of 151 cases and review of the literature with special emphasis on recurrence. Oral Surg Oral Med Oral Pathol Oral Radiol Endod 2010 Sep;110(3):357-363.

5. Walters JD, Will JK, Hatfield RD, Cacchillo DA, Raabe DA. Excision and repair of the peripheral ossifying fibroma: a report of 3 cases. J Periodontol 2001 Jul;72(7):939-944.

6. Mishra MB, Bhishen KA, Mishra R, Mishra S. Peripheral ossifying fibroma. J Oral Maxillofac Pathol 2011 Jan;15(1):65-68.

7. Batsakis JG. Non-odontogenic tumors: clinical evaluation and pathology. In: Thawley SE, Panje WR, Batsakis JG, Lindberg RD, editors. Comprehensive management of head and neck tumors. 2nd ed. Philadelphia (PA): WB Saunders; 1999. p. 1641-1642.

8. Cuisia ZE, Brannon RB. Peripheral ossifying fibroma - a clinical evaluation of 134 pediatric cases. Pediatr Dent J 2001 May-Jun;23(3):245-248.
9. Passos M, Azevedo R, Janini ME, Maia LC. Peripheral cemento-ossifying fibroma in a child: a case report. J Clin Pediatr Dent 2007 Fall;32(1):57-59.

10. Kumar SK, Ram S, Jorgensen MG, Shuler CF, Sedghizadeh PP. Multicentric peripheral ossifying fibroma. J Oral Sci 2006 Dec;48(4):239-243.

11. Moon WJ, Choi SY, Chung EC, Kwon KH, Chae SW. Peripheral ossifying fibroma in the oral cavity: CT and MR findings. Dentomaxillofac Radiol 2007;36(3):180-182.

12. Marx RE, Stern D. Oral and maxillofacial pathology: a rationale for diagnosis and treatment. Chicago (IL): Quintessence; 2003. p. 23-25.

13. Zhang W, Chen Y, An Z, Geng N, Bao D. Reactive gingival lesions: a retrospective study of 2,439 cases. Quintessence Int 2007 Feb;38(2):103-110.

14. Buchner A, Hansen LS. The histomorphologic spectrum of peripheral ossifying fibroma. Oral Surg Oral Med Oral Pathol 1987 Apr;63(4):452-461.

15. Bhaskar SN, Jacoway JR. Peripheral fibroma and peripheral fibroma with a calcification: report of 376 cases. J Am Dent Assoc 1966 Dec;73(6):1312-1320.

16. Zain RB, Fei YJ. Fibrous lesions of the gingiva: a histopathologic analysis of 204 cases. Oral Surg Oral Med Oral Pathol 1990 Oct;70(4):466-470.

17. Gardner DG. The peripheral odontogenic fibroma: an attempt at clarification. Oral Surg Oral Med Oral Pathol 1982 Jul;54(4):40-48. 